\title{
Shelf life quality of Labisia pumila extract and effect of granulation on dissolution rate
}

\author{
Aidee Kamal Khamis ${ }^{1}$, Harisun Ya'akob ${ }^{2}$, Nor Farahiyah Aman Nor ${ }^{2}$, Siti Nor Azlina Abd Rashid ${ }^{1}$, \\ Maizatulakmal Yahayu², Aziela Hanim Zolkopli ${ }^{2}$ \\ ${ }^{1}$ Innovation Centre in Agritechnology for Advanced Bioprocessing (ICA), \\ Universiti Teknologi Malaysia, Pagoh Hub, 84600 Pagoh, Johor, Malaysia. \\ ${ }^{2}$ Institute of Bioproduct Development, Universiti Teknologi Malaysia, 81310 Johor, Malaysia.
}

\begin{abstract}
Lyophilized from plants extract is a process to prolong the amounts of phytochemicals in a solid form. The bioactive compound in LP, which is Gallic acid should be stable and bioavailable during the downstream processing such as drying process in order to achieve its optimum health benefits. Therefore, this study focuses on the impact of lyophilize methods such as spray drying followed by granulator method in order to determine the stability of bioactive compound in LP during drying and storage. After the powdered produce, it will test on the model of human digestion (dissolution study) either the amounts of phytochemicals still remain stable. Finally, shelf-life quality analysis and the dissolution rate (capsule size 0 and 1) were carried out. The results obtained show the methods employed in this study can be used for analysis of quality content and dissolution tests of LP capsules. For LB in shelf-life quality study, parameters for appearance and TYMC showed no significant difference after 3 months. For $\mathrm{pH}$, the slight decrease in $\mathrm{pH}$ level will increase the number of TAMC in powder form. Compared to granule form, the $\mathrm{pH}$ level more consistent and the number of TAMC also in a control condition. The dissolution of capsules containing powder and granulated of LP showed a high percentage of bioactive compound released into the dissolution medium, although the bioactive compound content of herbal products (capsule size 1) was found to be half that of capsules size 0 . Through observation for both capsules size content of LP, the maximum dissolution was achieved after 100 $\min$.
\end{abstract}

Keywords: Shelf life quality, Granulation, Dissolution time, Labisia pumila and Gallic acid.

\section{INTRODUCTION}

Lyophilized from plants extract is a process to prolong the amounts of active ingredients or phytochemicals in a solid form. This lyophilized process will focus on spray drying, freeze-drying and granulation. Plants mainly consist bioactive compound that responsible for health beneficial effects. However, the good bioactive active components have to be protected from environment delay degradation and stabilize them during formulation and storage. In addition, plant extract in the powder form offering wider application in the product formulation compared to the liquid form.
The spray drying yields a fine powder with generally poor handling properties such as poor aqueous solubility, wettability, sink ability, therefore often followed by agglomeration process to tackle this problem because this process is able to form higher particle size and porous morphology which are desired properties in terms of high-quality powder.

Labisia pumila (LB) has been extensively used to assist childbirth and during the postpartum period [1]. Other studies show that this plant has anti-oxidant [2] and antiinflammatory properties due to its presence of phenolic compound [3]. Moreover, this plant able to exert uterotrophic effect and regulates body weight gain by

Corresponding Author: Aidee Kamal Khamis, Innovation Centre in Agritechnology for Advanced Bioprocessing (ICA), Universiti Teknologi Malaysia (UTM), Phone no.: +6012-7749054. Email add: aideekamal@utm.my 
modulating the secretion of adipocytes in adipose tissues [4]. The bioactive compound in LP should be stable and bioavailable during the downstream processing such as drying process in order to achieve its optimum health benefits. Therefore, this study focuses on the impact of lyophilized methods such as spray drying followed by granulator method in order to determine the stability of bioactive compound in LP during drying and storage. After the powdered produce, it will test on the model of human digestion (dissolution study) either the amounts of active ingredient or phytochemicals still remain stable.

\section{MATERIALS AND METHOD}

\section{A. Powder and granulation process}

Extraction ratio 1:10 of LP in 4 hours with extraction temperature $105-112^{\circ} \mathrm{C}$. Spray Drying (Niro Spray Dryer, Gea, Germany) at $180^{\circ} \mathrm{C}$ with spraying speed 30L/hours. Strea-1, Gea Nyro from Germany were used for the granulation process in 30 minutes. Monohydrate as main material added with Polyvinyl povidone (PVP) $\mathrm{K} 30$ as a binder coating with LP powder to produce granulation form. The final size of granules is in between 100-150 $\mu \mathrm{m}$. Powder and granules of LP, were pack $500 \mathrm{mg}$ in capsules size 0 and 1 . Finally, the dissolution rate and shelf life quality analysis were carried out [5].

\section{B. Shelf life quality analysis}

\section{Appearance}

The appearance of the LP extract powder was analyzed using observation in 3 months. The colour and its changes were recorded [6].

\section{2. $\mathrm{pH}$}

Weight $20 \mathrm{~g}$ powder and granule of LP in a plastic bottle and add $50 \mathrm{ml}$ distilled water. Shake for a while and leave it standing overnight (more than 16 hours). Calibrate the $\mathrm{pH}$ meter using buffer $\mathrm{pH} 4.00$ and $\mathrm{pH}$
7.00. Shake the sample and read the $\mathrm{pH}$ value [6].

\section{Sterilization}

Sterilizer was first cleaned with cotton soaked in $95 \%$ ethanol to ensure microbe-free sterilizing environment. Petri plates and pipette were washed with distilled water and dried. Petri plates were then placed in an oven (Memmert, Germany) at $180^{\circ} \mathrm{C}$ for $2 \mathrm{hr}$ [7].

\section{Serial dilution}

The serial dilution technique was employed according to the work by [8][9] with slight modifications. For the observation of mould and yeast, $1 \mathrm{ml}$ of bakery product was transferred to $100 \mathrm{ml}$ of sterilized distilled water. It gave dilution of 1:10. Briefly, $1 \mathrm{ml}$ of suspension from 1:10 was transferred to second test tube which gave $1: 100$ dilutions. Similarly $1: 1,000,1: 10,000$, and 1:100,000 dilutions were made. Dilutions were transferred to the sterilized Petri plates containing media. Then these Petri plates were incubated at $30 \pm$ $2^{0} \mathrm{C}$ for 3-7 days for microscopic and macroscopic identification.

\section{Total aerobic microbial count (TAMC), Coliform, Salmonella and Escherichia coli}

Enumeration of TAMC was done using nutrient agar (NA). Eosin methylene blue (EMB) agar was used for the coliform count, Salmonella agar was used for Salmonella count, MacConkey Agar (MAC) was used for Escherichia coli. All cultures were incubated in duplicate at $37^{0} \mathrm{C}$ for 24 hours except for coliform organism(s) which were incubated at $37^{\circ} \mathrm{C}$ and $44^{\circ} \mathrm{C}$ for 24 hours. All media used were prepared according to the manufacturers' instructions.

\section{Total yeast and mould count (TYMC)}

Potato dextrose agar was prepared by weighing $4 \mathrm{~g}$ of potato dextrose agar and poured it into a beaker. About $100 \mathrm{ml}$ of water was added and heated for 2-3 min. Continuous stirring was provided to the solution during heating to make homogenous mixture. Malt extract agar was prepared by dissolving $2 \mathrm{~g}$ of malt extract and $2 \mathrm{~g}$ of agar in distilled water to make the volume up to 100 $\mathrm{ml}$. The solution was mixed and gently heated till boiling. After preparation of saturated solutions, $10 \mathrm{ml}$ of the solution was poured in three test tubes. The test 
tubes were then covered tightly with cotton plugs. This medium was then autoclaved at about $15 \mathrm{lbs}$ and $121^{\circ} \mathrm{C}$ for $15 \mathrm{~min}$. After autoclave, media from test tubes were poured into freshly sterilized Petri plates and set to cool. After incubation plates, numbers of Petri plates were counted and multiplied by dilution factor to find out the number of spores per gram of a sample [8][9].

No. of spores $/ g=$ No. of colonies $\times$ Dilution factor $(1)$ Dilution factor $=$ Reciprocal of dilution (e.g., $\left.10^{-5}=10^{5}\right)$.

\section{i. Identification}

Fungi were identified on the basis of morphological and cultural characteristics such as the colour of the colony, surface, appearance according to the methods described in [10].

ii. Percentage contribution of each species

To find out percentage contribution following formula was used:

$\%$ Contribution $=\underline{\text { Total no. of CFU of an individual species }}$ total number of $\mathrm{CFU}$

x 100

- CFU: colony-forming unit

\section{Dissolution Rate Analysis}

The dissolution rate of LP for granulated and nongranulated samples at different concentration was studied in $0.1 \mathrm{~N}$ hydrochloric acid $(900 \mathrm{~mL})$ using USP Type 2 (M/S Labindia DS 8000) dissolution rate apparatus (Chowdry et. al., 2011). The paddle stirrer was set to $50 \mathrm{rpm}$ with the depth of $25 \mathrm{~mm}$ at $37 \pm 1^{\circ} \mathrm{C}$. $5 \mathrm{~mL}$ samples were taken out from each tube for 10 minutes intervals using $0.45 \mu \mathrm{m}$ filter and analysed using HPLC. The sample withdrawn was replaced with the fresh solution at each time of sampling. The cumulative percentage of bioactive compound from in vitro dissolution testing is shown as in Equation (1-3). All experiments were conducted in triplicate [11].

Concentration of bioactive compound $(\mu \mathrm{g} / \mathrm{ml})$ $=($ slope $\mathrm{x}$ absorbance $)) \pm$ intercept $\begin{aligned} & \text { Amount of bioactive released } \mathrm{mg} / \mathrm{ml} \\ & \text { Concentration } \mathrm{x} \text { Dissolution bath volume } \mathrm{x} \text { Dilution factor }\end{aligned}$
1000
$\begin{aligned} & \text { Cumulative percentage release } \\ & \frac{\text { Volume of sample withdrawn }(\mathrm{ml})}{\text { Bath volume }(\mathrm{V})} \times \mathrm{P}(\mathrm{t}-1)+\mathrm{Pt}\end{aligned}$

Where,

$\mathrm{Pt}=$ Percentage release at time $\mathrm{t}$

$\mathrm{P}(\mathrm{t}-1)=$ Percentage release previous to ' $\mathrm{t}$ '

\section{RESULT AND DISCUSSION}

For LB extract (powder form) in shelf-life quality study, parameters for appearance, TYMC, Coliform, Salmonella and Escherichia coli showed no significant difference after 3 months' time duration. For $\mathrm{pH}$, related to the number of TAMC there are significant different results. In powder form (Figure 1), the decrease of $\mathrm{pH}$ from 5.50 to 5.20 will affect the number of TAMC in the powder form. The number of TAMC increased from 1.5 x $10^{3} \mathrm{CFU} / \mathrm{g}$ to $2.5 \times 10^{3} \mathrm{CFU} / \mathrm{g}$ simultaneously by the $\mathrm{pH}$ decrease. The number of TAMC increased because at the lower $\mathrm{pH}$, in general the aerobic microbes will be more suitable and comfortable to survive [12].

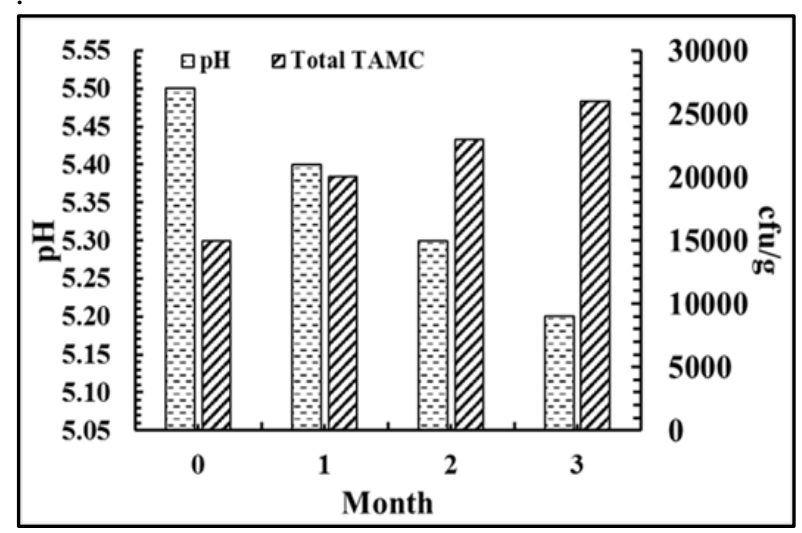

Figure 1. Labisia pumila shelf life (Powder) 


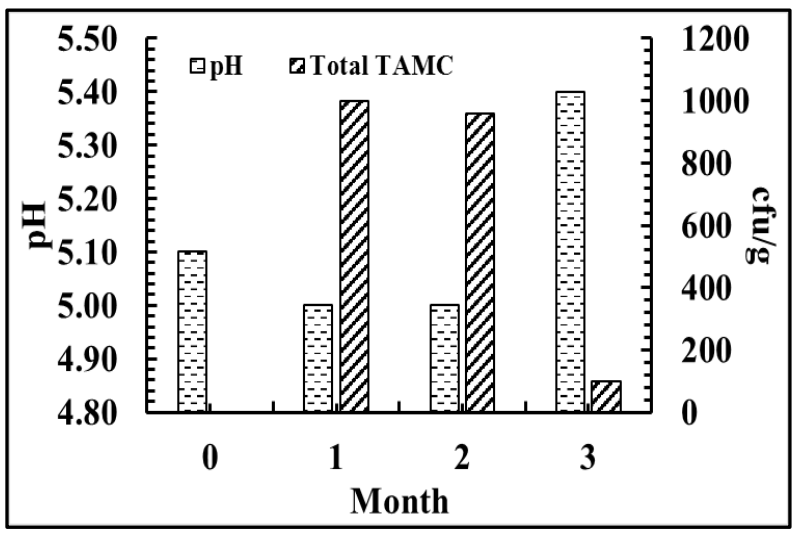

Figure 2. Labisia pumila shelf life (Granule)

For LB shelf life in granular form (Figure 2), $\mathrm{pH}$ between 5.10 to 5.00, in two months' time duration, shows that the number of TAMC also consistency in between 900 to $1000 \mathrm{CFU} / \mathrm{g}$. Start from month 3, the $\mathrm{pH}$ increased rapidly from 5.00 to 5.40 which affected the decreased of TAMC from 900 to 100 CFU/g. This significant result explains according the TAMC which is under pH 5.0 is hard to survive as reported by [13].

Figure 3 and 4 shows the dissolution profile of the capsule containing LP extract powder $(500 \mathrm{mg})$ in size 0 and 1 . These dissolution results have shown that the bioactive compound which is Gallic alcid simultaneously absorb into the waterbased solutions. Capsule size 1 was selected for better application base on the earlier dissolution which is 10 minutes faster than size 0 . The main reason for size 1 dissolution faster than size 0 is because the surface area is higher than size 0 . The significant area of surface which contribute to the faster dissolution was supported by [14]. Both sizes will achieve maximum dissolution rate after 100 minutes of application.

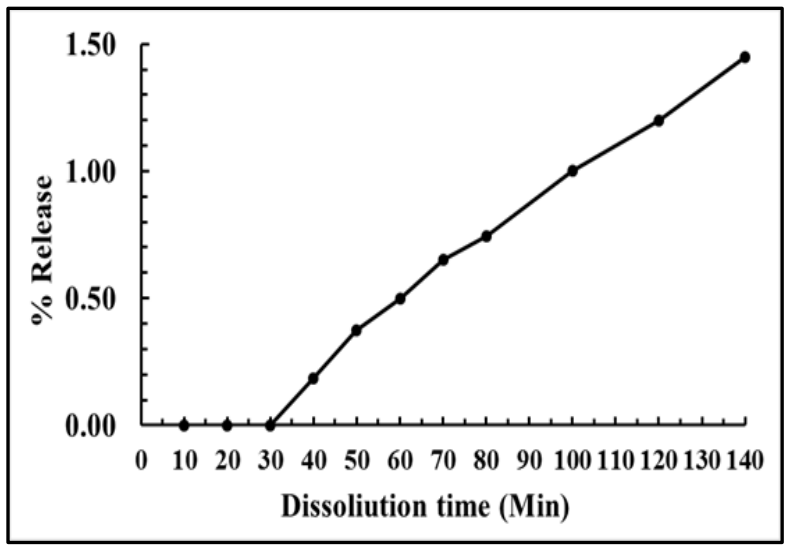

Figure 3. The dissolution profile of capsule containing LP extract powder $(500 \mathrm{mg})$ with capsule size 0

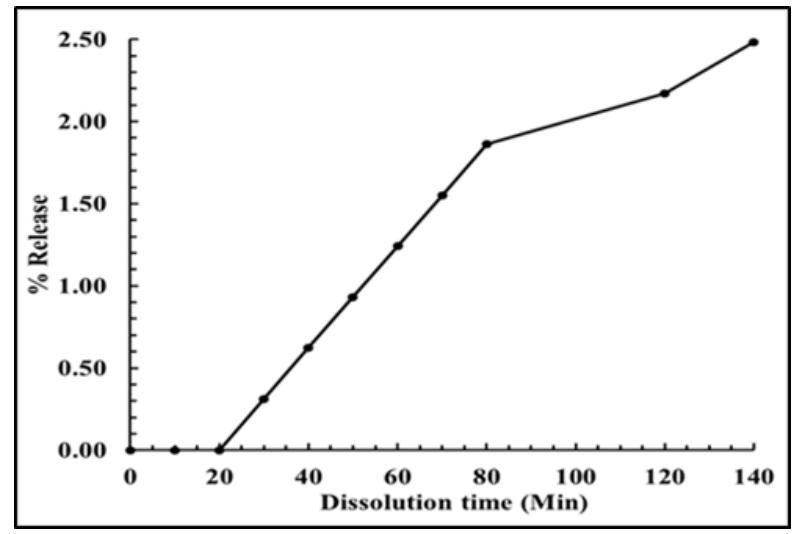

Figure 4. The dissolution profile of capsule containing LP extract powder $(500 \mathrm{mg})$ with capsule size 1

For dissolution profile of capsule containing LP extract granule $(500 \mathrm{mg})$ in size 0 and 1 shown in Figure 5 and 6. Capsule size 1 was selected for better application base on the earlier dissolution which is 10 minutes faster than size 0 . Similar reason as explain before, surface area is the main factor for the dissolution rate [15]. For size 1, after 20 minutes application time, the $\%$ of bioactive compound release will consistent with time compared to size 0 , where the $\%$ release will increase from time to time.

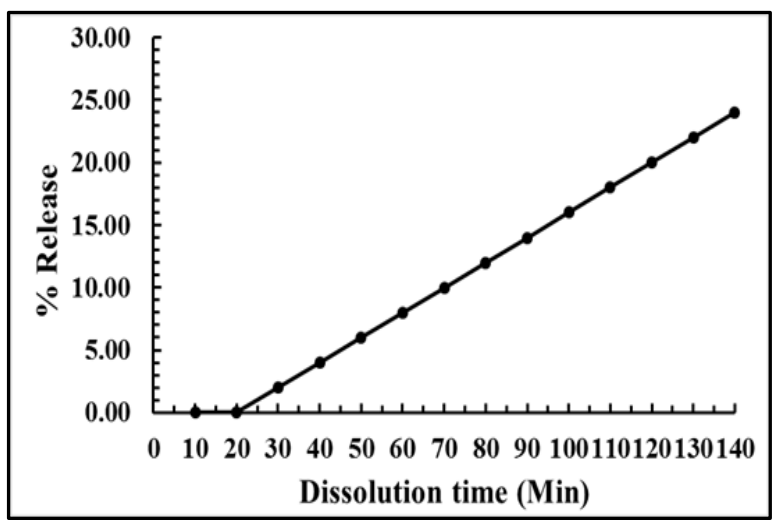

Figure 5. The dissolution profile of capsule containing LP granulated extract powder $(500 \mathrm{mg})$ with capsule size 0 


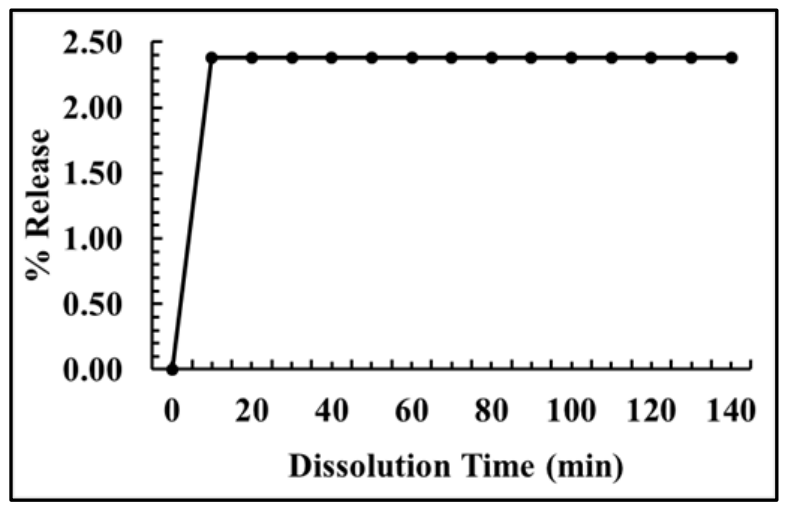

Figure 6. The dissolution profile of capsule containing LP granulated extract powder $(500 \mathrm{mg})$ with capsule size 1

\section{CONCLUSION}

The results obtained allow us to suggest the methods employed in this study can be used in the quality control (analysis of quality content and dissolution tests) of LP capsules since the methods were demonstrating selectivity, linearity and range, precision (repeatability and intermediate precision), accuracy and robustness. For $\mathrm{pH}$, the slight decrease in $\mathrm{pH}$ level will increase the number of TAMC in powder form. Compared to granule form, the $\mathrm{pH}$ level more consistent and the number of TAMC also in a control condition. The dissolution of capsules containing powder and granulated of LP showed a high percentage of bioactive compound released into the dissolution medium, although the bioactive compound from LB (capsule size 1) was found to be half that of capsules size 0 . Through observation for both capsules size content of LP, the maximum dissolution was achieved after $100 \mathrm{~min}$.

\section{ACKNOWLEDGMENTS}

The authors acknowledge the financial support from the Ministry of Education under HICOE Research Grant no. RJ130000.7809.4J274, Malaysia.

\section{REFERENCES}

[1] Wan Ezumi Mohd Fuad, Hasnan Jaafar, Siti Amrah Sulaiman, 2017. The effects of Malaysian herb Labisia pumila var alata on oestrous cyclicity and reproductive parameters of nulliparous rats. UKM Journal Article Repository. 46(10), 1721-1726.
[2] Siti Nor Fathilah, Shahrum Abdullah, Norazlena Mohamed, Ahmad Nazrun Shuid, 2012. Review article: Labisia pumila prevents complications of osteoporosis by increasing bone strength in a rat model of postmenopausal osteoporosis. Evidence complimentary and alternative medicine. Volume 2012, ID 948080.

[3] Jamaluddin N, Hasham R. 2015. Properties of aqua Labisia pumila extract on prostate cancer cell lines. Jurnal Teknologi. 2, 61-6.

[4] M. E. Nadia, A. S. Nazrun, M. Norazlina, N. M. Isa, M. Norliza, S. Ima Nirwana, 2012. The antiinflammatory, phytoestrogenic, and antioxidative role of Labisia pumila in prevention of postmenopausal osteoporosis. Advanced In Pharmacological Sciences. Vol. 2012, ID 706905.

[5] Chandrasekaran A.R., Jia C.Y., Theng C.S., Muniandy, Muralidharan S., Dhanaraj A. 2011. Invitro studies and evaluation of metformin marketed tablets-Malaysia. Journal of Applied Pharmaceutical Science, 1 (05), 214-217.

[6] M. E. Nadia, A. S. Nazrun, M. Norazlina, N. M. Isa, M. Norliza, S. Ima Nirwana, 2012. The antiinflammatory, phytoestrogenic, and antioxidative role of Labisia pumila in prevention of postmenopausal osteoporosis. Advanced In Pharmacological Sciences. Vol. 2012, ID 706905.

[7] Nik Hussain, Nik Hazlina, Abdul Kadir, Azidah, 2013. Potential Role of Labisia pumila in the prevention and treatment of chronic diseases. Journal of Food Research. Vol. 2, 1053-1055.

[8] Juan Wang, Chun Xu, Binglan Li, Meizhen Wang, 2018. Uncertainty evaluation for total aerobic microbial count of Jingfang granule. Western Pacific Region Index Medicus. 21(2), 363-365.

[9] Meenal Khana, UVS Teotia, Yogendra Singh, 2018. Effect of storage on microbial quality of non-sterile liquid dosage form. Journal of Pharmacognosy and Phytochemistry. 7(2), 479-481.

[10] Abigail B. Synder, John J. Curey, Randy W. Worobo, 2019. Association of fungal genera from spoiled processed foods with physicochemical food properties and processing conditions. Food Microbiology. Vol. 23, 211-218. 
[11] Chowdry K.P.R., Udaya Chandra D., Mahesh N., Macha Reddy T., Venkata Gopiah K. 2011. Enhancement of dissolution rate and formulation development of pioglitazone - ABCS Class II Drug. Journal of Pharmacy Research, 4(11), 3862-3863.

[12] Haryati Ahmad Hairi, Noor Suhaili Mohd Sofi, Sitti Nor Khamdiah Khodari, Jamia Azdina Jamal, Isa Naina Mohamed, Ahmad Nazrun Shuid, 2016. Therapeutic effects of Labisia pumila on estrogendeficiency related disorders: An evidence based review. International Journal of Pharmacology. 12, 451-460.

[13] Philip Pui- Li Yen, David D. Kitts, Anubhav Pratap Singh, 2018. Journal of Food Science. Vol. 3(8), 2039-2046.

[14] Zhang Yingjie, Fu Jie, Xiuyang Lu, 2015. A greener process for gallic acid production from tannic acid hydrolysis with hydrochloric acid. Asian Journal of Chemistry, 27 (9), 3328-3332.

[15] Kanshupak Noppharat, Napaphak Jaipakdee, Ekapol Limpongsa, 2019. Development of herbal capsules containing mulberry leaf and black tea extracts using the modified liquid solid techniques. International Journal of Applied Pharmaceutics. Vol. 4 (11), 25-31. 